\title{
Laser Marking of PLA FDM Printed Products
}

\author{
IONEL DANUT SAVU ${ }^{1}$, SORIN VASILE SAVU1, NICUSOR-ALIN SIRBU ${ }^{2}$, \\ MIRELA CIORNEI ${ }^{3}$, ROBERT CRISTIAN MARIN ${ }^{1}$, DANIELA IOANA TUDOSE ${ }^{4 *}$ \\ ${ }^{1}$ University of Craiova, 13 A.I. Cuza Str., 200585, Craiova, Romania \\ ${ }^{2}$ NRDI for Welding and Material Testing - ISIM Timisoara, 30 Mihai Viteazu, 300222, Timisoara, Romania \\ ${ }^{3}$ Territorial Labor Inspectorate of MH, 3 Carol I Str., 220099, Drobeta Tr. Severin, Romania \\ ${ }^{4}$ University Politehnica of Bucharest, 313 Splaiul Independentei, 060042, Bucharest, Romania
}

\begin{abstract}
The paper aimed to reveal, qualitatively and quantitatively, the modifications suffered by the PLA during the complex heating cycle specific to the $3 D$ printing followed by laser marking. The obtained results showed that the melting point of the PLA decreases from $162.2^{\circ} \mathrm{C}$ (which is specific to $P L A$ filament) to $153.1^{\circ} \mathrm{C}$ after the $3 D$ printing process and to $149.7^{\circ} \mathrm{C}$ after the laser heating. The glass transition suffered the same lowering after the printing process but an important increasing after the laser heating. The elastic modulus evolution proved a decreasing of the plasticity and that is hapenning when the material suffers an increasing of its rigidity. The elongation viscosity was analyzed and its values were decreasing with the increasing of the temperature that happened on the material. The decreasing was produced by the reduction of the elasticity, when the chain branches are decreasing their length. The decreasing is more pronounced with the increasing of the temperature. The ratio between the loss modulus to the storage modulus and quantifies the way in which the PLA absorbs and disperses energy moves its peak from $65^{\circ} \mathrm{C}$ (curve specific to the PLA filament) to $45^{\circ} \mathrm{C}$ (curve specific to the last layer deposited by $3 D$ printing process and re-heated by laser beam for marking). The peak means the lowest storage modulus, which is a measure of elastic response of a material, so the transition from glass to high elasticity moves to the lower temperatures.
\end{abstract}

Keywords: $3 D$ printing using PLA, laser heating, relaxation modulus, crystallization, decreased plasticity, elongation viscosity

\section{Introduction}

3D printing technology is dedicated to the fabrication of prototypes and products by adding a material (polymers, metals, etc.) in successive layers [1] with specific densities. The deposited layers correspond to the sections a 3D geometrical model. Building a piece in layer by layer mode, the technology becomes very efficient when create very complex geometries that are difficult to be produced by removal of material technologies. Fabian [2] reported application of the 3D technology for the reconstruction of nasoalveolar cleft; also, in medicine, Tancu [3] reported the use of 3D printing in dental applications, both products being elements of prosthetics with very complex shapes $[4,5]$. Probably with a more important impact than application in medicine is the application of 3D technology in engine technique and in 2019 Vasilescu [6] used the 3D printing to create complex gear piece. All these examples show important advantage of using 3D printing technology in rapid prototyping and in production, as well.

$3 \mathrm{D}$ printing uses polymer or metal filament or powder consumable to deposit, most of the cases being related to the deposit of PLA or ABS polymer [7]. Dimonie [8] proposed even starch as precursor in filament material synthesis and the obtained results were encouraging. Sometimes, when produce a prototype or a ready-to-use piece, the $3 \mathrm{D}$ process is followed by the marking of the product. Most of the times the marking is done by laser and that means a reheating of the $3 \mathrm{D}$ product.

The succession of the two heating processes is expected to produce modifications in the characteristics of the deposited polymer. Gonata [9] proposed an experimental procedure for the

*email: daniela.tudor@upb.ro 
determination the elastic characteristics of polymeric materials, also Tabacu [10] studied some numerical procedures for the improvement of the structural response of thermoplastic manufactured parts. The Polylactic Acid (PLA) is an ecologic thermoplastic material, having good strength and high modulus $[11,12]$. It has a glass-transition of about $55^{\circ} \mathrm{C}$ and a melt temperature around $175^{\circ} \mathrm{C}$. Anyway, for efficient $3 \mathrm{D}$ printing, PLA requires $20-30^{\circ} \mathrm{C}$ over the melting temperature $[8,9]$. The range of processing temperatures is generally very narrow, because PLA suffers a decreasing of its own molecular weight, due to specific ,chain cutting” reactions. Important modifications on the elasticity and plasticity of PLA were recorded for repetitive heating processes and they were reported by Zapciu [13], Srithep [14], Farah [15], Trhlíková [16] and Matos [17]. Maroti [18, 19] reported modifications of the physical properties of PLA during 3D printing, modifications which affect its functionality in medical implants. Due to these conclusions the paper aims to bring results of short evaluations of the modification of different characteristics of the PLA which was deposited in 3D printing followed by laser heating (dedicated to marking) process [20, 21]. It will be used Differential Scanning Calorimetry (DSC) techniques to evaluate the thermal characteristics which give relevant information on the plasticity of the PLA in different stages related to the complex process of 3D printing followed by laser heating for marking [22, 23].

\section{Materials and methods}

Scope. The scope of research was the evaluation of the modifications suffered by the PLA during successive heating which is specific to 3D printing process followed by laser heating dedicated to the marking of the product. First, FDM 3D printing process was used to elaborate a random chosen product which is often used in mechanical devices. Secondly, being a product which will be offered on the market for selling, it is necessary to be marked with specific information. The heating for marking was done by using laser-diode device. Taking account of the reported modifications [1-19], during the research, by thermal analysis, it was targeted: the elastic modulus, the elongation viscosity, the relaxation modulus and the heat flux. They gave important information on the modifications suffered by the PLA. More, macroscopic analysis was applied in order to evaluate the quality of the heated area.

The heating cycle applied to the PLA filament was according to Figure 1. After each heating step the material was thermally analysed by using DSC technique.

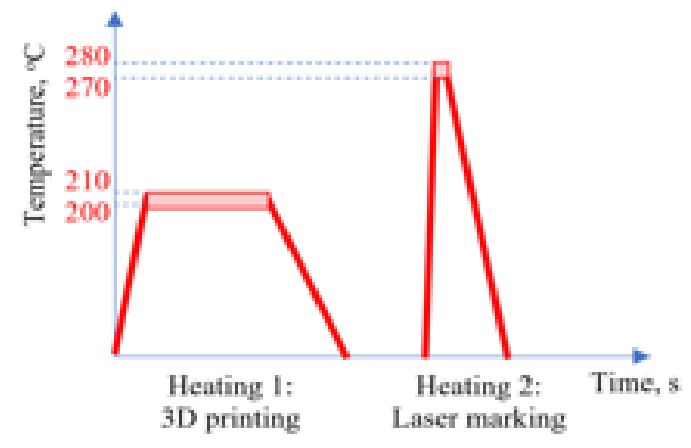

Figure 1. Double heating cycle

Equipment and parameters. For the 3D printing process, it was used a 3D Da Vinci 2A Duo printer, using 2 filaments with $1.75 \mathrm{~mm}$ diameter (Figure 2). As used printing parameters, they were the filament temperature which was set to $205 \pm 10^{\circ} \mathrm{C}$ and the print bed temperature which was set to $70 \pm 5^{\circ} \mathrm{C}$. The both values of the temperatures came from previous research. The filling of the deposition was set to $50 \%$, which gives good performance for a rapid prototyped piece. 


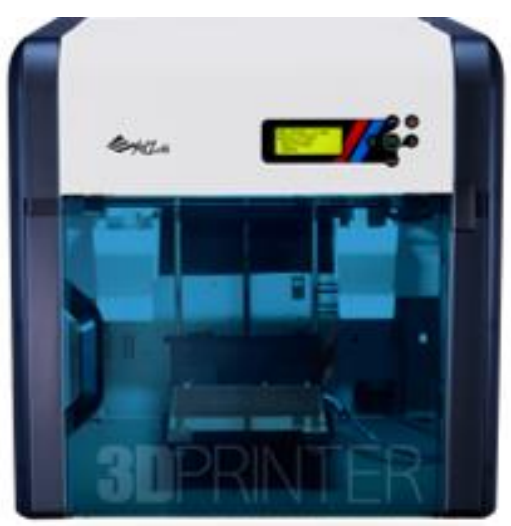

a. Printer

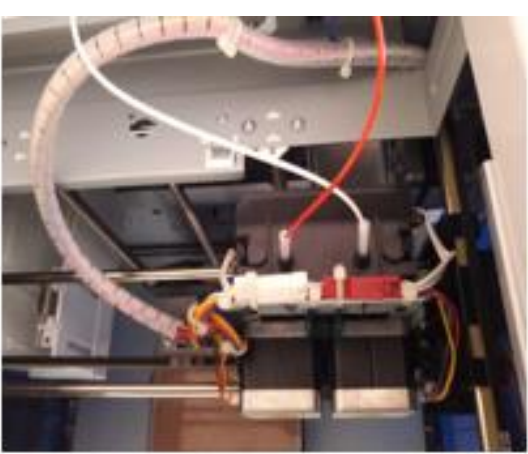

b. Two PLA filaments

Figure 2. Da Vinci 2A Duo printer

For the laser heating it was used $650 \mathrm{~nm}$ - InGaAsP laser-diode device, having $1000 \mathrm{~mW}$ power (Figure 3). The laser device was mounted on stereo-microscope (4x) to facilitate the operation of heating. Angle of $70^{\circ}$ was set for the laser ray axis.

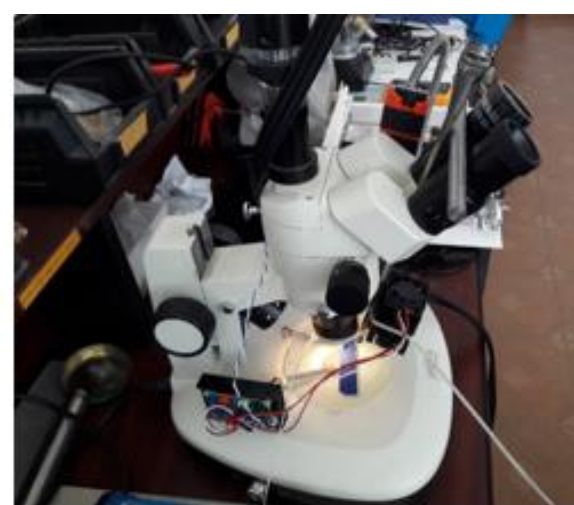

a. Experimental laser device

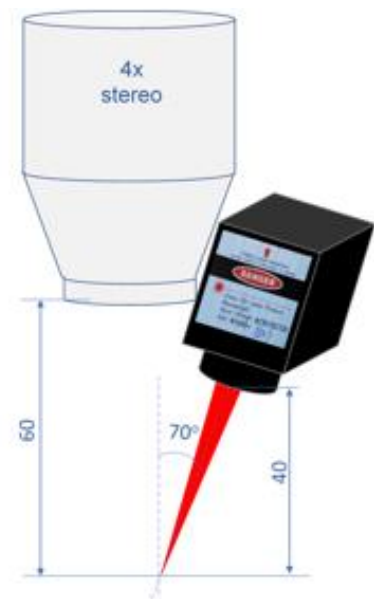

b. Geometry and dimensions

Figure 3. Diode laser device mounted on stereo-microscope

The device was calculated in order to have correct wave length and maximum efficiency. The density of energy produced by the laser beam inside the polymer product is given by:

$$
d Q_{\text {polymer }}=c \rho T_{\text {marking }} \mathrm{dx}
$$

Around the focal point action area, the thermal field produced by the laser beam can be expressed by:

$$
d T_{\text {marking }}={\frac{d Q_{\text {polymer }}}{c \rho(4 \pi a t)^{1 / 2}}}^{-\frac{(h-x)^{2}}{4 a t}}
$$

In eq. (1) and (2) Qpolymer is the heat flux given in $\mathrm{W} / \mathrm{m}^{2}, \rho$ is the density of the polymer given in $\mathrm{kg} / \mathrm{m}^{3}$, c is the heat capacity of the polymer at constant pressure, given in $\mathrm{J} /(\mathrm{kg} . \mathrm{K})$ and a represents the diffusivity of the polymer.

In that case, the developed temperature in time is:

$$
T(h, t)=\int_{-L}^{L} d T=\frac{T_{\text {marking }}}{(4 \pi a t)^{1 / 2}} \cdot \int_{-L}^{L} e^{-\frac{(h-x)^{2}}{4 a t}} d x
$$


The model was used to set the temperature for the marking process and the result was confirmed by Kasap [24]. According to Kasap the slope of the $\lambda=650 \mathrm{~nm}$ laser diode, when the external quantic efficiency is $\eta$ ext $=0.1$ has the value of:

$$
\Delta \mathrm{P}=0.956 \cdot \eta_{\text {ext }} \cdot \Delta \mathrm{I}
$$

and for the electron charge of:

$$
\mathrm{e}=1.6 \cdot 10^{-19} \mathrm{C}
$$

the slope becomes:

$$
\Delta \mathrm{P}=0.956 \cdot 0.1 \cdot \Delta \mathrm{I}=0.096 \cdot \Delta \mathrm{I}
$$

The threshold current (to start the emission of the laser diode) depends on the temperature.

$$
I_{t h}(T)=I_{o} \cdot e^{\frac{T}{T_{o}}}
$$

To calculate the initial current I_o and the temperature T for the InGaAsP laser diode it should be used a threshold current I_th of $25 \mathrm{~mA}, 40 \mathrm{~mA}$ şi $65 \mathrm{~mA}$, la $0^{\circ} \mathrm{C}, 25^{\circ} \mathrm{C}$ and $65^{\circ} \mathrm{C}$, according to the producer catalogue. At $\mathrm{T}=0^{\circ} \mathrm{C}$ the initial current is:

$$
I_{o}=25 \mathrm{~mA} \text {. }
$$

By replacing the Ith $=40 \mathrm{~mA}$ at $\mathrm{T}=25^{\circ} \mathrm{C}$, it can be calculated a temperature of $\mathrm{T} 0=53^{\circ} \mathrm{C}$.

If introduce that value in equation (4) results for $\mathrm{T} 0=53^{\circ} \mathrm{C}$ and $\mathrm{T}=65^{\circ} \mathrm{C}$ :

$$
\mathrm{I}_{\text {th }}=88 \mathrm{~mA} \text {, }
$$

While the specification of the producer is $75 \mathrm{~mA}$. In this case it is necessary to increase to $88 \mathrm{~mA}$ the threshold current, even if the laser diode is forced, in order to have maximum efficiency in the heating of PLA process.

\section{Materials and preparation for analysis}

The consumable for the 3D printing process was commercial filament of PLA, having $1.75 \mathrm{~mm}$ in diameter and the samples for analysis were taken from the piece (Figures $4 \mathrm{a}$ and $4 \mathrm{~b}$ ) printed by double heating cycle presented in Figure 1. The samples were cleaned for analysis by using isopropyl alcohol (C3H8O, IUPAC - propan-2-ol) after the 3D printing process and after the laser heating process.

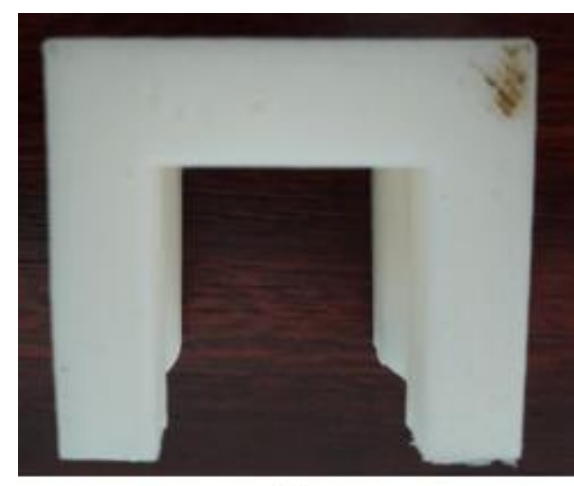

a.

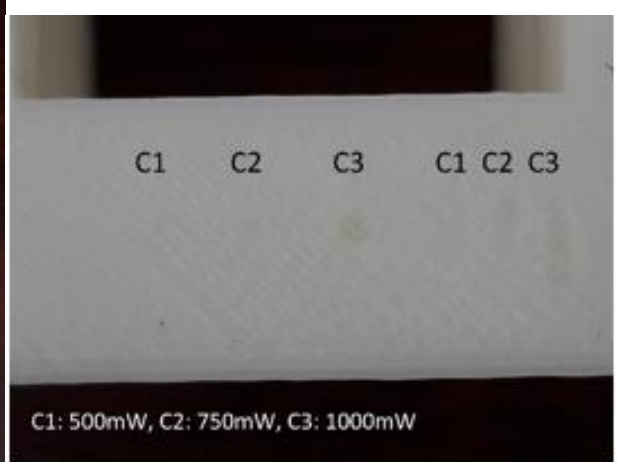

b.

Figure 4. Printed piece and the laser melted areas for different laser power values 


\section{Analysis}

DSC analysis was carried out using NETZSCH HP Phoenix 204 equipment. Three type of samples were taken: A - from the PLA filament, B - from the 3D printing deposited PLA and C - from the area burned by laser for marking process. The conditions created for the investigations are listed next: heating and cooling were performed in inert atmosphere; the heating process started from ambiental temperature $\left(22^{\circ} \mathrm{C}\right)$ to $218^{\circ} \mathrm{C}$; the heating rate was set at $10^{\circ} \mathrm{C} / \mathrm{min}$; the cooling process meant the decreasing of the probe temperature to $-10^{\circ} \mathrm{C}$ with a rate of $10^{\circ} \mathrm{C} / \mathrm{min}$, followed by isothermal regime at $-10^{\circ} \mathrm{C}$ for $5 \mathrm{~min}$; last step was a heating at $400^{\circ} \mathrm{C}$ with a rate of $10^{\circ} \mathrm{C} / \mathrm{min}$. It was measured the heat flow, in order to evaluate the crystallization, the glass transition and the melting of the PLA. It was measured the elastic modulus to understand the level of plasticity and the elongation viscosity which gives important information on the plasticity of the material.

\section{Results and discussions}

Aspect of the probes. The pieces printed in the conditions presented above showed high roughness of the surface, given by the medium resolution of printing (Figure 5). The roughness helped the absorption of the laser beam incident power, the absorbed power being over $30 \%$ of the incident power.

The images of the C1, C2 and C3 prints are presented in Figures $6 a, b, c$ and d. They show the shape and the dimensions of the spot generated by the laser beam with different incident power values, all 4 for being generated in $1 \mathrm{~s}$ of interaction.

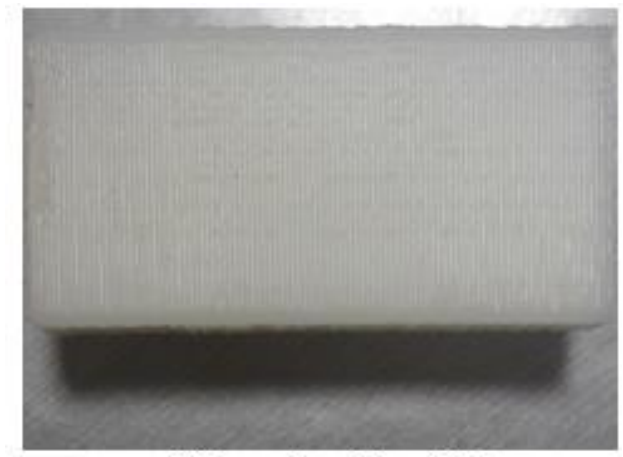

a. Printed surface $(2 \mathrm{x})$

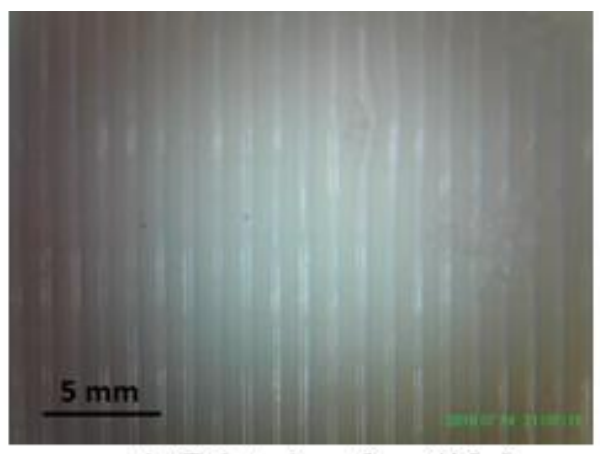

b. Printed surface (10x)

Figure 5. The piece generated by $3 \mathrm{D}$ printing

As expected, the dimensions of the prints (average diameter and average penetration) increased with the set incident power. The shape, which is closed to an ellipse, is not circular due to the angle of $70^{\circ}$ (angle involved by the experimental device microscope-laser source shape and dimensions).

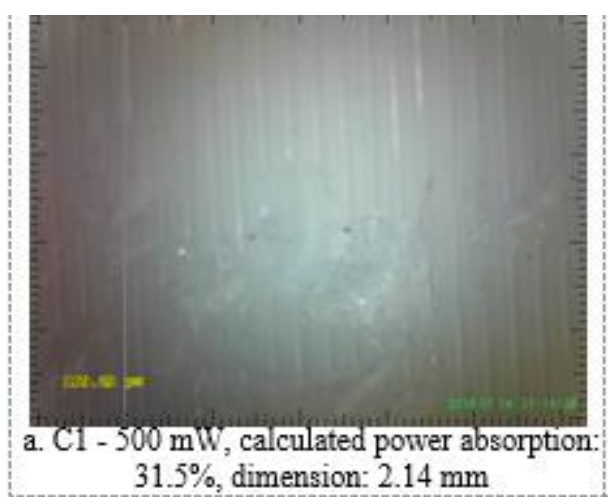

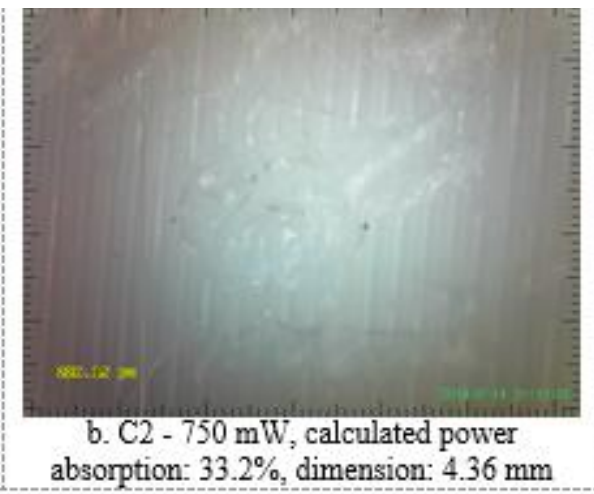




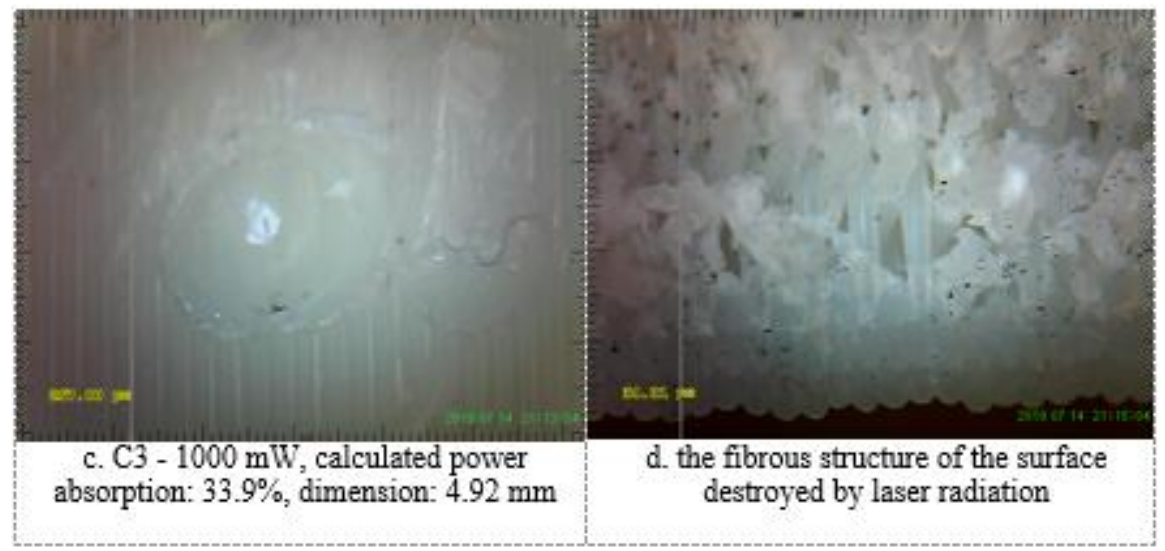

Figure 6. Prints generated by the laser heating

The amount of power absorbed by the PLA surface was critical to the material, which became foamy and sparks of material were recorded due the laser heating (Figure 7).

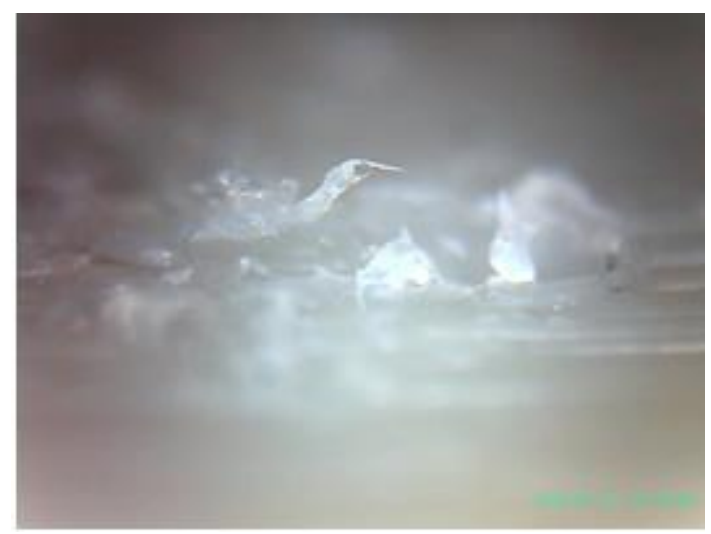

Figure 7. Sparkling appearance of the area melted by laser radiation

Energy received during the 3D printing process. The PLA filament receives amount of heat during the 3D printing. Part of it is accumulated into the PLA and participates to the melting of the filament and part of it is transferred to the environment. The energy balance inside the PLA when heat for the 3D printing is given by the rate of change of 3 energies: $\frac{\partial E}{\partial t}$ - the rate of change of the energy which action on the surface of the material, $\frac{\partial E_{\text {accumulated }}}{\partial t}$ - the rate of change of the energy which is accumulated into the PLA and $\frac{\partial E_{\text {transf_env }}}{\partial t}$ - the rate of change of the energy which is reflected by the PLA and is transferred to the environment.

$$
\frac{\partial E}{\partial t}=\frac{\partial E_{\text {accumulated }}}{\partial t}+\frac{\partial E_{\text {transf } \_n v}}{\partial t}
$$

The accumulated energy produces the melting of the PLA filament. But the PLA filament is introduced into the heating nozzle by digital motor, with specific travel speed. That means that the filament suffers modification of the pressure from 0 to a value given by the set travel speed (PPLAfil). The existence of the pressure modifies the melting of the filament. The critical temperature of PLA, which defines the transition from solid to liquid when heating is applied and from liquid to solid when the molten material is cooled down, is generally expressed by the Tait equation for the solid state (just below the melting point) 


$$
\mathrm{T}_{s-1}=\mathrm{b}_{5}+\mathrm{b}_{6} \cdot\left(\mathrm{P}_{a m b}+\mathrm{P}_{P_{L A} f i l}\right)
$$

where $b_{5}$ is the glass transition temperature for $P=0$ and $b_{6}$ is the rate of change of glass transition temperature with pressure; they describe the change of transition temperature with pressure. According to Padilha [25] and Chang [26] the estimated values for $b_{5}$ and $b_{6}$ are $440.44 \mathrm{~K}$, respectively 0.0048 $\mathrm{K} / \mathrm{MPa}$.

The situation is different for the laser heating for marking. The pressure is the ambiental one and the transition temperature can be calculated with:

$$
\mathrm{T}_{(\mathrm{s}-\mathrm{l})}=\mathrm{b}_{5}+\mathrm{b}_{6} \cdot \mathrm{P}_{\mathrm{amb}}
$$

The difference between the two temperatures was revealed by DSC test to draw the heat flow within the PLA filament and the heat flow into the deposited PLA and deposited plus laser heated PLA. When tested the filament (A), it was observed that, during the applied heating for testing, the glass transition temperature with its specific heat capacity change $\left(57-58^{\circ} \mathrm{C}\right)$, the exothermic crystallization (range: 85 $110^{\circ} \mathrm{C}$ ) and the endothermic melting (range: $165-180^{\circ} \mathrm{C}$ ), according to Figure 8 .

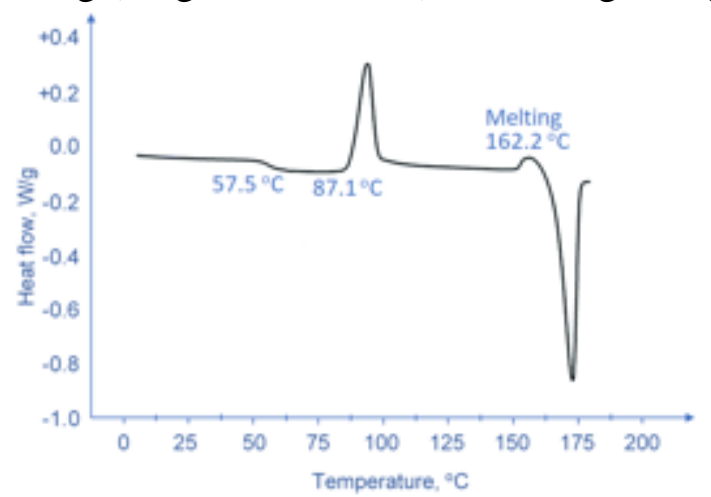

Figure 8. Crystallization of the PLA filament

Same test was performed on the PLA after the 3D printing heating (B) and after the laser heating for marking (C). The results are shown in Figure 9 and they are similar to other reported results from Maroti $[18,19]$.

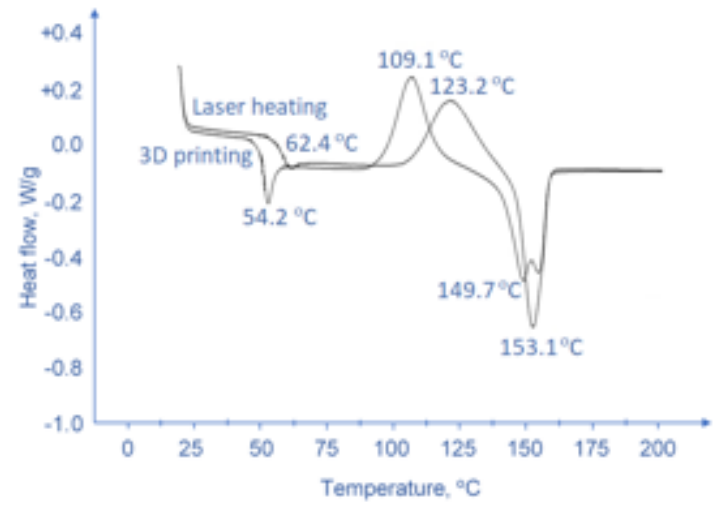

Figure 9. Crystallization of the deposited PLA (by 3D printing) and of the deposited PLA followed by laser heating

After each applied heating, the glass transition temperature changed: after the 3D printing heating the glass transition temperature decreased with about $3{ }^{\circ} \mathrm{C}$; after the laser heating a strange increasing of the glass transition temperature with over $8^{\circ} \mathrm{C}$ has been recorded. The decreasing of the heat flow, after the $3 \mathrm{D}$ printing process, confirmed the expectations of stiffening due to high rate heating and cooling. 
The later increasing cannot be explained, taking into account that the laser heating was very fast, even if the cooling was natural. A factor that could provide influence is the deposition of the next layer during the 3D printing.

When look at the curve recorded during the testing of the 3D deposited PLA, it can be observed a double melting peak for PLA. Such double peak is actually the second cold crystallization peak before the complete melting of the PLA crystals and that could have as reason the melting of two types of PLA lamellar crystals (having different dimensions). If the interpretation is correct, the next deposited layer produces pseudo-annealing of the previous layer.

To better understand the modification the elastic modulus was evaluated for the three (A, B and C) situations. Figure 10 shows the recorded evolution of the elastic modulus.

It can be observed in Figure 10 that the material becomes more fragile with each new heating. The increasing of the elastic modulus means a decreasing of the plasticity and that is hapenning when the material suffers increasing of its rigidity.

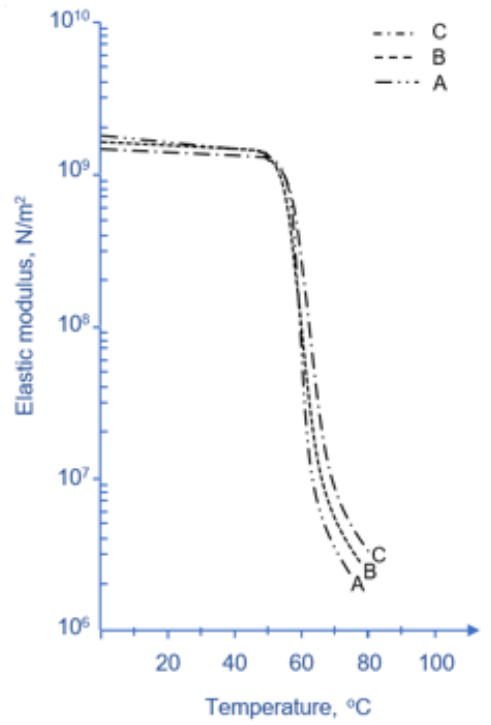

Figure 10. Recorded elastic modulus

Same result was revealed by the evolution of the elongation viscosity, measured on 3 samples of the deposited PLA and 3 samples of the deposited and laser heated PLA. The curves of elongation viscosity are shown in Figure 11.

It can be observed that in the first 0.6 s the elongation viscosity has very low increasing, comparing to the next 7-8 s.

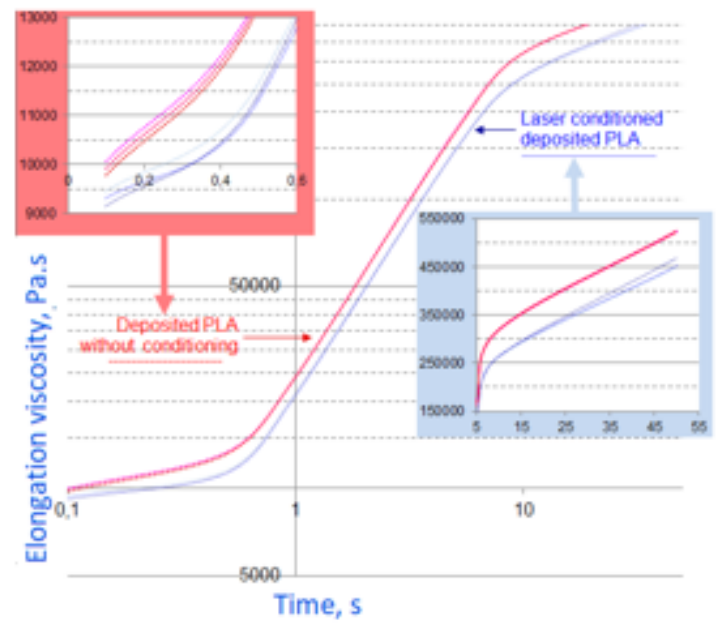

Figure 11. Elongation viscosity curves 
The values are in the range: 9000-13000 Pa.s. Similar evolution has been revealed to start at $7.8 \mathrm{~s}$. For the next 8-10 s the elongation viscozity increased from 150000 to $350000 \mathrm{~Pa}$.s.

In the same time it can be noted that the curves for the 3D deposited PLA are at higher values comparing to the curves recorded for the 3D printed and laser heated PLA. That means that the plasticity of deposited PLA is higher before the laser heating process than after.

Probably a better image is given by the damping which is the ratio of loss modulus to the storage modulus and quantifies the way in which the PLA absorbs and disperses energy. The tangent delta is shown in Figure 12. The recorded curves show the lowest values for the PLA filament. The deposition of the first layer is followed by the next layers and that means that the first layer is heated once again by the next layer. The new heating is a pseudo-annealing but, even this, the material shows loss of plasticity and gain of elasticity.

The last layer is not re-heated by the 3D printing process and it shows an increasing of the loss modulus which means that the material is a stiffened. Same increasing has been recorded after the laser heating, as well. Even if the peaks are almost the same, they were recorded in different moments. A faster peak proves a lower plasticity of the material.

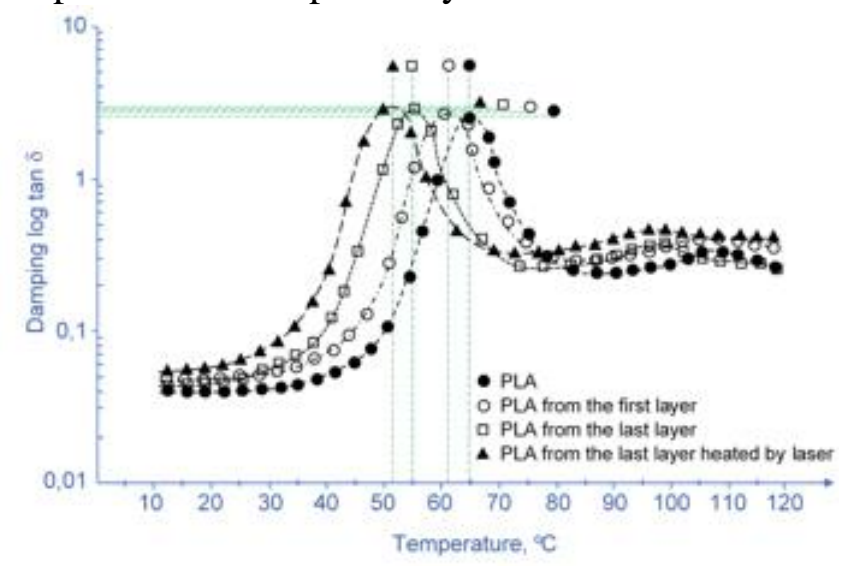

Figure 12. Tan delta

(ratio of loss modulus

to the storage

modulus)

\section{Conclusions}

3D printing uses consumables which support thermal cycle consisting of heating up to fluid-viscous state followed by natural cooling and later, during the next layer deposition, a new heating, which is below the melting point occurs. After the 3D printing the piece is subjected to locally heating due to the marking process. The literature confirms modifications of the PLA material with each new applied heating. The experimental program showed that the PLA becomes foamy when the laser heating is applied. With each new heating the melting point decreases from $162.2^{\circ} \mathrm{C}$ (which is specific to PLA filament) to $153.1^{\circ} \mathrm{C}$ after the $3 \mathrm{D}$ printing process and to $149.7^{\circ} \mathrm{C}$ after the laser heating. The glass transition temperature suffered the same lowering after the printing process but an important increasing after the laser heating. It shows that the material has lost its plasticity, becoming tougher and more fragile, after the laser marking. The type of the lamellar crystals influenced the melting of the PLA during the laser heating. A double melting peak for PLA has been recorded and such double peak is produced by the second cold crystallization peak before the complete melting of the PLA. Each peak is given by a type of PLA lamellar crystals (having different dimensions). The elastic modulus evolution, recorded for the PLA filament before the process and for the heated PLA, after the 3D printing and after the laser heating, proved a decreasing of the plasticity and that is hapenning when the material suffers an increasing of its rigidity. By DSC techniques the elongation viscosity was analyzed and its values were decreasing with the increasing of the temperature that occurred on the material. The decreasing was produced by the reduction of the elasticity, when the chain branches are decreasing their length. The decreasing is more pronounced with the increasing of the temperature. Lower heating during marking process is bringing higher elongation viscosity, so higher plasticity of the analysed area. A new proof of the loss of plasticity was the damping values, which show the evolution of the ratio between the loss modulus to the storage modulus and quantifies the way in which the PLA absorbs and disperses energy. 
With each new heating process the peak of the damping is going down from $65^{\circ} \mathrm{C}$ (curve specific to the PLA filament) to $45^{\circ} \mathrm{C}$ (curve specific to the last layer deposited by 3D printing process and re-heated by laser beam for marking). The decreasing of the position of the peak's values means that the balance between the loss modulus and the storage modulus is done at lower temperatures. The peak means the lowest storage modulus, which is a measure of elastic response of a material, so the transition from glass to high elasticity moves to the lower temperatures. An important effect has the reheating of a deposited layer, when the next layer is applied. The effect is similar to an annealing heat treatment and the plasticity of the material is partially restored.

\section{References}

1. MOTOMANCEA, A., BUCURESTEANU, A., PRODAN, D., Execution of Non-Metallic or Metallic Duplicates, cast with 3D Scanners and 3D Printers, Mater. Plast., 56(1), 2019, 6-10

2. FABIAN, Z., KADAR, K., PATONAY, L., NAGY, K., Application of 3D Printed Biocompatible Plastic Surgical Template for the Reconstruction of a Nasoalveolar Cleft with Preoperative Volume Analysis, Mater. Plast., 56(2), 2019, 413-415

3. PANTEA, M., TANCU, A.M.C., TOTAN, A. IMRE, M., TANASE, M., 3D Printed Dental Models. A comparative analysis, Mater. Plast., 56(1), 2019, 51-54

4. TARNITA, D., BOBORELU, C., GEONEA, I., MALCIU, R., GRIGORIE, L. TARNITA, D., In vitro Implantation Technique Based on 3D Printed Prosthetic Prototypes, EUROINVENT ICIR 2018, vol. 374, 10.1088/1757-899X/374/1/012060

5. TARNITA, D., BOBORELU, C., POPA, D., RUSU, L., The three-dimensional modelling of the complex virtual human elbow joint, Romanian J. of Morphology and Embryology, vol. 51, 2010, p. 489495

6. VASILESCU, M.D., Constructive and Technological Consideration on the Generation of Gear Made by the DLP 3D-Printed Method, Mater. Plast., 56(2), 2019, 440-444

7. JIMENEZ, M., ROMERO, L., DOMNIGUEZ, I.A., DEL MAR ESPINOSA, M., DOMINGUEZ, M., Additive Manufacturing Technologies: An Overview about 3D Printing Methods and Future Prospects, Complexity in Manufacturing Processes and Systems 2019, Volume 2019, Article ID 9656938, https://doi.org/10.1155/2019/9656938

8. DIMONIE, D., DAMIAN, C., TRUSCA, R., RAPA, M., Some Aspects Conditioning the Achieving of Filaments for 3D Printing from Physical Modified Corn Starch, Mater. Plast., 56(2), 2019, 351-359

9. GOANȚĂ, V., HADĂR, A., LEIȚOIU, B., Experimental Procedure Designed to Determine the Elastic Characteristics of Fiber Reinforced Polymeric Composite Materials, Mater. Plast., 47(4), 2010, 450-456

10. TABACU, ŞT., HADĂR, A., MARIN, D., DINU, G., IONESCU, D.S., Structural Performances of Thermoplastic Manufactured Parts, Mater. Plast., 45(1), 2009, 113-118

11. JEM, K.J., TAN, B., The development and challenges of poly (lactic acid) and poly (glycolic acid), Advanced Industrial and Engineering Polymer Research, Volume 3, Issue 2, April 2020, Pages 60-70, https://doi.org/10.1016/j.aiepr.2020.01.002

12. SAEIDLOU, S., HUNEAULT, M.A., LI, H., PARK, C.B., Poly (lactic acid) crystallization, Progress in Polymer Science 37 (2012) p. 1657- 1677

13.ZAPCIU, A., AMZA, C.G., RONTESCU, C., TASCA, G., 3D-Printed, Non-assembly, Pneumatically Actuated Mechanisms from Thermoplastic Materials, Mater. Plast., 55(4), 2018, 517520

14. SRITHEP, Y., NEALEY, P., TURNG, L.-S., Effects of annealing time and temperature on the crystallinity and heat resistance behaviour of injection moulded poly (lactic acid), Polymer Engineering and Science, 53(3), 2013, pp. 580-588

15. FARAH, S., ANDERSON, D.G., LANGER, R., Physical and mechanical properties of PLA, and their functions in widespread applications - A comprehensive review, Adv. Drug Deliv. Rev. (2016), http://dx.doi.org/10.1016/j.addr.2016.06.012 
16. TRHLÍKOVÁ, L., ZMESKAL, O., PSENCIK, P., FLORIAN, P., Study of the thermal properties of filaments for 3D printing, AIP Conference Proceedings 1752, 040027 (2016);

https://doi.org/10.1063/1.4955258

17. MATOS, B.D.M., ROCHA, V., DA SILVA, E.J., BARUD, H.D.S., Evaluation of commercially available polylactic acid (PLA) filaments for 3D printing applications, Journal of Thermal Analysis and Calorimetry, July 2019, Volume 137, Issue 2, pp 555-562

18. MARÓTI, P., VARGA, P., FERENCZ, A., UJFALUSI, Z., NYITRAI, M., Lőrinczy, D., Testing of innovative materials for medical additive manufacturing by DTA, Journal of Thermal Analysis and Calorimetry 136(3) · October 2018, DOI: 10.1007/s10973-018-7839-X

19. MARÓTI, P., KOCSIS, B., FERENCZ, A., NYITRAI, M., LÖRINCZY, D., Differential thermal analysis of the antibacterial effect of PLA-based materials planned for 3D printing, Journal of Thermal Analysis and Calorimetry, DOI: 10.1007/s10973-019-08377-4, online May 2019

20. SAVU I. D., SAVU S. V., SIRBU N. A., Heat affected zones in polymer laser marking, Journal of Thermal Analysis and Calorimetry, 2014, vol. 115, issue 2, p. 1427-1437

21. SAVU S. V., SAVU I. D., BENGA G. C., CIUPITU I., Improving functionality of Ti6A14V by laser technology surfacing, Optoelectronic and Advanced Materials, Rapid Communications, 2016, vol. 10, no. 9-10, p. 752-760

22. SAVU S. V., SAVU I. D., CIUPITU I., Thermal Analysis to Evaluate Ageing Process in Heated Tool and Electrofusion Welding of Polymer Pipes, Advanced Materials Research, 2014, vol. 837, p. 190-195

23. SIRBU N. A., SERBAN V. A., SAVU S. V., Influence of the ultrasonic microvibrations under the processing of the HDPE thermoplastic material, Mater. Plast., 65(4), 2014, 401-404.

24. KASAP, S.O., Optoelectronics and Photonics: Principles and Practices, Second Edition, 2013 Pearson Education

25. PADILHA JÚNIOR, E. J., DE PELEGRINI SOARES, R., MEDEIROS CARDOZO, N. S., Analysis of equations of state for polymers, Polímeros vol.25 no.3 São Carlos May/June 2015, http://dx.doi.org/10.1590/0104-1428.1621, ISSN 0104-1428

26. CHANG, R. Y., CHEN, C. H., SU, K. S., Modifying the Tait Equation With Cooling-Rate Effects to Predict the Pressure-Volume-Temperature Behaviours of Amorphous Polymers: Modelling and Experiments, Polymer Engineering and Science, July 1996, vol. 36, no. 13, p. 1789-1795

$\overline{\text { Manuscript received: } 6.02 .2020}$ 